This is an author produced version of a paper published in URBAN

FORESTRY \& URBAN GREENING. This paper has been peerreviewed but does not include the final publisher proof-corrections or journal pagination.

Citation for the published paper:

Tenngart Ivarsson, Carina \& Hagerhall, Caroline M.. (2008) The perceived restorativeness of gardens: assessing the restorativeness of a mixed built and natural scene type. Urban Forestry \& Urban Greening.

Volume 7: issue 2, pages 107-118. ISSN 1618-8667. http://dx.doi.org/10.1016/j.ufug.2008.01.001

Access to the published version may require journal subscription.

Published with permission from: Elsevier $\mathrm{GmbH}$.

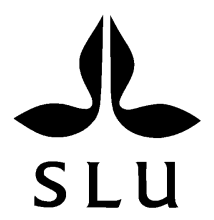

Epsilon Open Archive http://epsilon.slu.se 


\title{
The perceived restorativeness of gardens- Assessing the restorativeness of a mixed built and natural scene type
}

\section{${\text { Carina Tenngart } \text { Ivarsson }^{1} \& \text { Caroline M. Hagerhall }}^{2}$}

${ }^{1}$ Department of Work Science, Business Economics and Environmental Psychology, Swedish University of Agricultural Sciences. P.O. Box 88, SE- 23053 Alnarp, Sweden.

E-mail: carina.tenngart@1tj.slu.se (corresponding author)

${ }^{2}$ Department of Landscape Architecture, Swedish University of Agricultural Sciences. P.O. Box 58, SE- 23053 Alnarp, Sweden. E-mail: caroline.hagerhall@1tj.slu.se

\begin{abstract}
Natural environments have been found more restorative than built environments but studies have also highlighted mixed built and natural environments. The aims were to examine the perceived restorativeness of gardens, and evaluate the performance of the Perceived Restorativeness Scale, PRS, when applied to two examples from the same mixed built natural scene type rather than to a contrast between built and natural. The results show that the gardens are perceived restorative and the PRS also proved itself capable of discriminating between the two gardens. This points to the PRS being a useful tool and emphasizes the shortcomings of broad scene type definitions. The results show that one scene type can include environments that are significantly different in perceived restorativeness. This underlines the need to collect data on a greater number of both different scene types and examples within every type, as well as to have more controlled definitions of content and scene types to understand the relationship between the physical expression of a place and its potential of being restorative. The results show that the PRS is sensitive to place characteristics at subscale level, showing a high Being away score for both gardens and a Scope score that differed substantially. The results show a high correlation between restorativeness and preference.
\end{abstract}

\section{Key Words:}

Design; Preference; PRS; Restorative environments

\section{Introduction}

\subsection{The development of studies on restorative environments}

Landscape preference studies dates back to the 1960s but it was not until the work by Kaplan and Kaplan $(1982,1989)$ that the experience of the landscape and its physical attributes was related more directly to a psychological mode. This model now represents one approach to understanding restorative environments, and the model is based on information processing and cognitive functioning. In their work, identifying the underlying structure of preferences, the physical attributes involved came to play a key role with the possibility then to predict preference based on the environmental content. The results, from the large amount of preference studies made, have pointed to structural properties like topographic variation, the scale and openness of the scene and to particular attributes like water but the most significant factor has appeared to be the degree to which a scene is natural or man-made (see for example, Kaplan et al., 1972; Kaplan and Kaplan, 1982; Purcell and Lamb, 1984; Herzog, 1985, 1987; Kaplan, 1987; Kaplan and Kaplan, 1989). 
In the last 15 years research on environmental preference has also begun to take into consideration the effect of the environments on psycho-physiological well-being. This research has in one aspect followed the path set by the preference research, with environmental content as a very important factor both when formulating theory and conducting the experiments. In Kaplan's Attention Restoration Theory, ART (1995), nature is in the centre of the argument for the restorative experience. The idea in ART is that environments with particular characteristics could help people recover a depleted directed attentional capacity. Such restorative environments should have four characteristics; fascination, a sense of being-away, extent, and compatibility. All four characteristics are dependant on an interaction between the place and the observer. Fascination stands for a kind of involuntary attention (James, 1892), attention that does not demand mental effort and which is attracted by stimuli having directly fascinating qualities. It is here that nature is said to have the benefit over the built, by being full of non demanding but fascinating objects and processes. A feeling of being-away can naturally be induced by travelling to another place but it can also be imaginary. Also extent can be influenced by imagination. It is a sense of being in a large enough place where no boundaries are evident. Compatibility too is dependent on both physical and non-physical attributes in that high compatibility involves how well the content of the environment supports the needs and inclinations of the user. There is now indeed a large body of data showing that natural environments are more restorative than built environments (Ulrich et al., 1991; Hartig et al., 1991; Korpela and Hartig, 1996; Hernandez et al., 2001; Purcell et al., 2001). According to Scopelliti and Giuliani (2005, p. 426) restorativeness is 'the result of a complex place experience, in which cognitive, affective, social and behavioural components are considered together with the physical aspects of the environment'. This would also mean that the four different components in the ART theory would be likely to be of different strength as predictors of restorativeness in different situations. Herzog et al., (2003) have shown data pointing to this relative effectiveness of the predictors.

The majority of studies on restorativeness have been comparing a few built to natural scene types (see for example Laumann et al., 2001) in order to understand their restorative potential. There have been different suggestions of what nature should be most restorative; wilderness or everyday nature (Purcell et al., 2001, p. 103). Also results pointing to mixed built and natural scene types as perceived as very restorative have been presented (Peron et al., 2002).

\subsection{The evaluation of restorative environments}

Research on landscape preference and restorative environments thus seems to share a focus on physical attributes. This research also shares results pointing to natural environments as being more preferred and more restorative than built environments. Still, the definitions of the scene types and physical attributes involved are quite broad. These broad definitions are problematic particularly when trying to apply the results to practise and to the design of new environments. The important relationship between place and health is increasingly being recognized by academics, publich health practitioners, medical health professionals as well as by the general public, but it has still only begun to be examined (Williams, 1999, p. 2). When attempting to design restorative settings it is fundamental to know what physical aspects and key properties to work with in the design of the environment. To be able to meet this need we have to know more about the restorative potential of different environments, both on a more 
comprehensive level (including more scene types) as well as on a more detailed level (concentrating on one scene type). Research on these issues will provide us with better data for making informed decisions in the design process regarding restorative environments.

To acquire the knowledge on how to design restorative environments we need tools to evaluate the restorative potential of existing environments, relating theory with user perceptions and design options. A first step to developing such an instrument has already been taken. The Perceived Restorativeness Scale, PRS, was introduced in 1996 by Hartig et al. One of the main goals when developing the PRS was to provide designers with a measurement tool that could be used to assess the restorative potential of existing and proposed settings, and so to inform various kinds of design efforts (Hartig et al., 1997b). The PRS is based on the Attention Restoration Theory (Kaplan, 1995) and its four factors. The scale has been developed involving a number of different researchers and thus exists in slightly different versions. Hartig et al. (1997a, p.4) state that 'extent is treated by the Kaplans as a function of connectedness and scope' and in the first versions of the scale the subscales were Being Away, Fascination, Compatibility and Coherence (see for example Hartig et al., 1996; Korpela and Hartig, 1996; Hartig et al., 1997a; Hartig et al., 1997b). In Korpela and Hartig (1996) it is explained that the Coherence items are 'intended to tap an aspect of Extent'. In the study by Purcell et al. (2001) the subscale Scope was added. There are quite a few studies using the PRS and thus the validity and reliability of the PRS have been assessed (Hartig et al., 1996; Korpela and Hartig, 1996; Hartig et al., 1997a; Hartig et al., 1997b; Korpela et al., 2001; Purcell et al., 2001; Peron et al., 2002; Galindo and Hidalgo, 2005). Although the scale needs some further examination regarding its psychometric properties, it was considered an established instrument for the purposes of this study. The scale has shown consistent results regardless of different ways of presenting the sites (on-site, video or photographic slides) (Hartig et al., 1996; Hartig et al., 1997a; Hartig et al., 1997b).

The main purpose of this study was to examine the perceived restorativeness of the scene type garden, which is a mixed built and natural scene type. For added relevance the present study investigates the perceived restorativeness of two Swedish gardens, carefully chosen as they both are specifically made to be used in rehabilitation by people with stress related disorders. Both the perceived restorativeness and the preference of this scene type will be compared with other scene types represented in previous studies. In addition, by comparing two examples of the same scene type, the present study serves a methodological function in terms of examining whether the PRS is sensitive to differences in settings of the same scene type.

The gardens have both similarities and differences. Both gardens are sharply marked off from their surroundings and none of them are open to the public, but they differ much in size and the presence of houses nearby. An additional aim of this study is to elaborate on what possible results of differences in perceived restorativeness, also on subscale level, might relate to these similarities and differences in design. Presently there is limited existing research on such gardens regarding both their healing effects and the design of the gardens, and most research is of descriptive nature. (Health Council of the Netherlands and Dutch Council for Research on Spatial Planning, Nature and the Environment, 2004; Hartig et al., 1999). Still, the garden design is of uttermost importance when designing gardens in health care settings as divergences between patients' and designers' views of what is aesthetically pleasing might have unwanted effects, actually resulting in environments that may have a negative effect on people that are acutely stressed or mentally ill. (Ulrich, 1999, p. 66). 
Most previous studies are concerned with the psychometric properties of the PRS or the restorative experience (Hartig et al., 1996, Hartig et al., 1997a; Hartig et al., 1997b; Scopelliti and Giuliani, 2005). There are a few studies, like the present, which are focusing on the perception of the physical, restorative environment. Therefore it has been very important in this study to enable and to make close comparisons with the few previous studies conducted with this perspective (Purcell et al., 2001; Peron et al., 2002). Studies like the present one, aimed at identifying and elaborating on which scene types, and particular examples of scene types, people perceive as having the potential or not to be restorative are greatly needed to reassure an optimal sampling of environments. These more in detail controlled environments might then be used for instance in possible future studies measuring actual restoration effects, in terms of blood pressure levels and cognitive functioning, as opposed to the perceived restorativeness that is the scope of this study.

\section{Methodology}

\subsection{Judgements}

The version of the PRS used in this study was based on an original Swedish version by Hartig (Hartig, personal communication, October 2003), and was modified and expanded to be consistent with comparable studies (Purcell et al., 2001; Peron et al., 2002). The PRS used consequently had five subscales where Compatibility has 7 items (for example 'It is easy to do what I want here'), Being Away has 6 items (for example 'This place is a refuge from unwanted distractions'), Fascination has 7 items (for example 'This place awakens my curiosity'), Coherence has 4 items (for example 'Everything here seems to have a proper place') and Scope has 5 items (for example 'I find this place very spacious'). In addition to the 27 PRS items (two items are included in two subscales each) one question on preference was included ${ }^{1}$. Since the main focus of the study was to examine the perceived restorativeness of the gardens the preference question was judged after the PRS items. This approach was taken to minimize effects by this rating on the PRS score. Judgements were made on a 0 to 10 point Likert scale with $0=$ not at all and $10=$ completely, with every second number labelled. A within subjects design was chosen since it eliminates subject variability and thus has greater ability to detect an effect concerning differences between the two gardens and the PRS' ability to discriminate between them. To control for the problems that can occur in a within subjects design, such as order effects or learning effects, the environments were presented and rated in a balanced design.

\subsection{Study sites and stimuli}

Two different gardens in Sweden were chosen. The key selection criteria were the difference in size and the differing degree of built and natural character between the gardens. These criteria were seen as particularly relevant since they have previously been used in research on

\footnotetext{
${ }^{1}$ As a consequence of the result in 2001, (Purcell et al.), two items are included in two subscales each, Fascination \& Scope and Scope \& Compatibility. Three items, belonging to the subscales Being Away, Fascination and Scope \& Compatibility, were not present in the Swedish version and have been translated from the version in Purcell et al. (2001) by the authors. Also, from the Swedish version an item in Scope is included in the present version, which is not included in Purcell et al. (2001).
} 
restorative environments and the PRS. Both gardens have also been constructed to be used by people with stress related disorders.

The first garden, situated in Alnarp, is spacious and approximately 2 ha big with larger as well as smaller garden rooms. The parts closer to the buildings are more ordered and the parts further away are more natural and wild in their appearance. There are many possibilities for views within the garden without buildings (see Figs. 1 and 2).

The second garden, situated in Umeå, is a 13 x 17 meters small and detailed courtyard garden. There are no natural areas and views at eye-level always include the building (see Figs. 1 and $3)$.

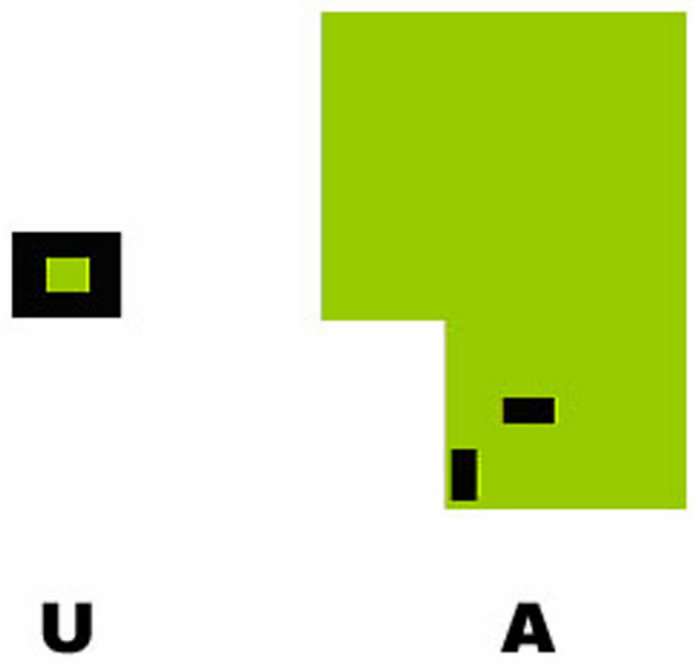

Figure 1. Illustration of the size difference and enclosure characteristics between the courtyard garden in Umeå, left, and the garden in Alnarp, right. Buildings are shown in black and areas of vegetation in green.

In all 852 colour photographs were sampled from the gardens on sunny summer days with similar conditions in light and cloudiness. A first reduction was made by removing photos with low technical quality and ensuring similar conditions in light and weather in all pictures. The remaining 105 photos in total (75 for Alnarp and 30 for Umeå) were put in 12 subgroups for each garden, based on a grid like structure laid out over the maps of the gardens, making sure all parts of the gardens were covered. 18 judges, 9 of them landscape architects and 9 of them with other academic backgrounds, individually ranked the photos in every subgroup resulting in one best example for every subgroup. Consequently the final sample consisted of 12 photos for each garden, shown in Figure 2 and 3. As many previous studies on perception of landscape this study is based on visual stimuli. Other aspects of sensory stimulation are interesting in relation to the perception of gardens, but as stated in the introduction, the scale has shown consistent results regardless of the sites were presented on-site or with visual media.

Subjects were told that they would be shown two different environments, one at a time. The photos for the first garden were initially shown one at a time for 15 seconds, with respondents 
told to just view the images and try to get a feeling of the place. Then all photos of this garden were shown simultaneously, as in Figure 2 . This overall picture stayed on the screen $(1.9 \mathrm{x}$ $1.4 \mathrm{~m}$ ) while subjects made their judgements. When all subjects had completed the questions, using as much time as they needed, the same procedure was repeated for the second garden, Figure 3. The presentation order of the two gardens was rotated between the 9 rating sessions.
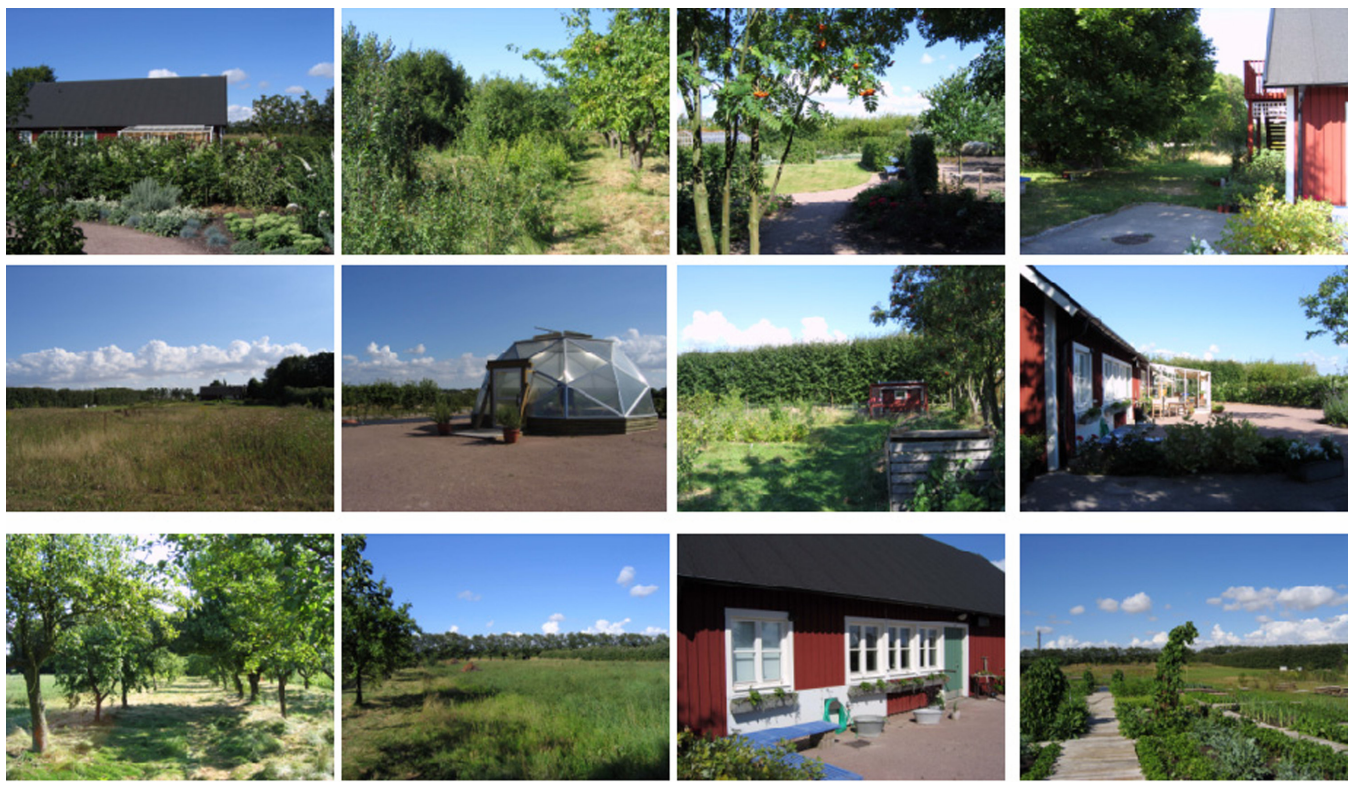

Figure 2. The selected photos for the garden in Alnarp.
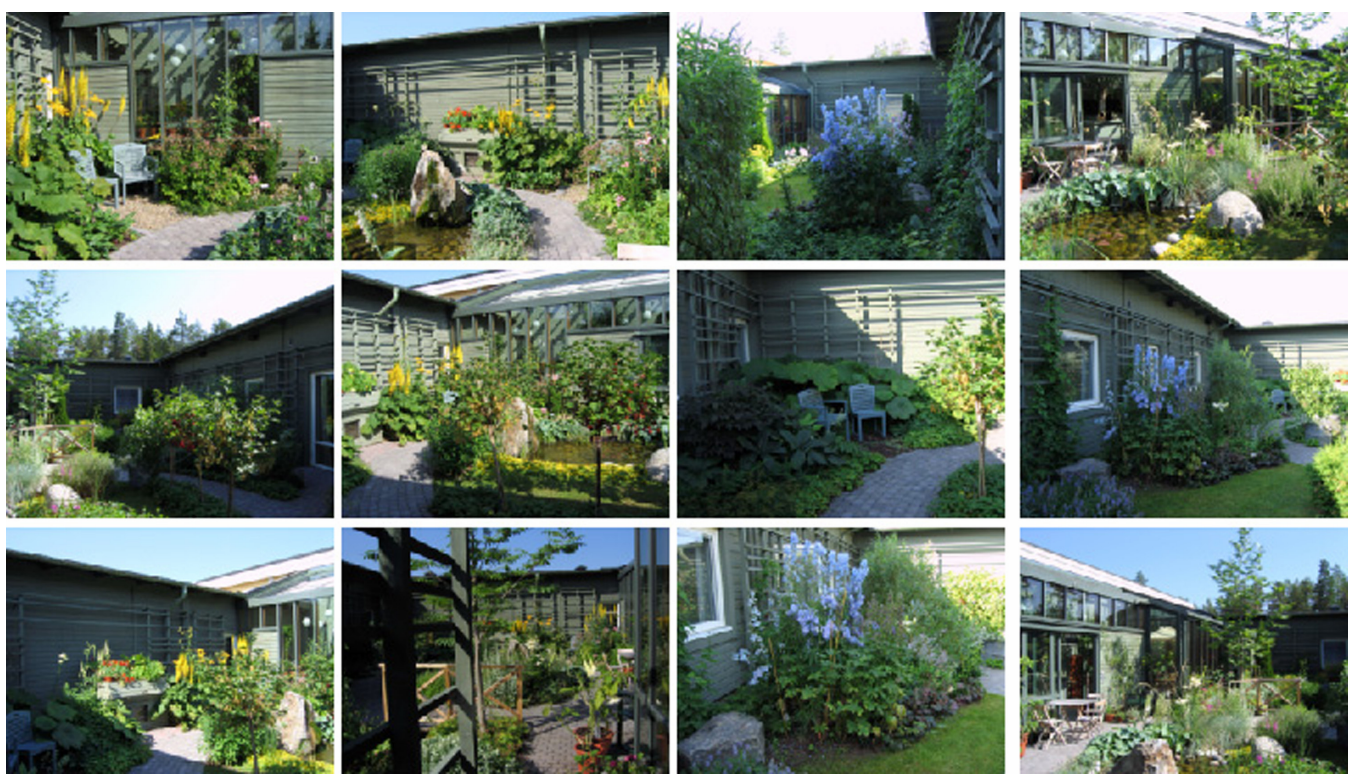

Figure 3. The selected photos for the garden in Umeå. 


\subsection{Subjects}

41 psychology students from the University of Lund and 33 landscape architecture students from the Swedish University of Agricultural Sciences participated. Most of the studies using the PRS have used undergraduate students as subjects. It was therefore considered an advantage to use the same type of subjects to enable comparisons of results. However, we hypothesized that landscape architecture students might differ in one aspect; they might be particularly sensitive to detecting visual differences in outdoor environments. Differences in architectural appraisals between architects and laypersons are well known phenomena and it has been established that these groups take notice of different physical attributes (Gifford et al., 2000). Therefore contrasting the judgments of landscape architecture students against another group of students could be experimentally valuable when examining if the PRS can discriminate between more similar environments like two gardens. More women than men participated, though in similar proportions for both respondent groups. Subjects were taken through the procedure in groups $(n=3-12)$ of either landscape architecture students or psychology students. 39 subjects viewed the garden in Umeå first and 35 subjects viewed the garden in Alnarp first. In all, the procedure took approximately 30 minutes to complete. Participation was voluntary and neither course credits nor monetary compensation was provided.

\section{Results}

\subsection{Factor analysis}

Like in studies with a similar main focus (Purcell et al., 2001 and Peron et al., 2002), that is the perceived restorativeness of different scene types rather than the psychometric properties of the PRS, it was essential to first establish whether or not the Overall PRS score could be used as a single valid value representing the contents of the PRS scale. Therefore, as in previous studies an unrotated principal components analysis was performed on the 27 PRS items, for all subjects but for each of the two gardens separately. The results showed a strong first factor accounting for 43.4 percent of the variance for the Umeå garden and 39.5 percent for the Alnarp garden. Three items had a low loading on this first factor, and at the same time a high loading on a second factor accounting for 10.8 and 10.2 percent respectively of the variance, for the two gardens. Of these three items two belonged to the Coherence subscale and one to the Compatibility subscale. This is a structure generally very consistent with the studies by Purcell et al. (2001) and Peron et al. (2002) where a single factor solution was appropriate and accounted for $40.1 \%$ and $42 \%$ of the variance respectively. In Purcell et al. (2001) the second factor accounted for $2.1 \%$ of the variance.

Continuing the examination of the scale's performance a reliability analysis of the internal consistency of each a priori subscale was performed and showed high consistency with earlier studies. As can be seen in Table 1 the reliability was generally high, but with lower values for Scope, particularly so for the Alnarp garden, and for Coherence. A low reliability for Scope, 0.63 and 0.57, was also found in the studies by Purcell et al. (2001) and Peron et al. (2002), and low reliability has also previously been found for Coherence, 0.68, 0.60 and 0.61 (see Korpela and Hartig, 1996; Purcell et al., 2001 and Peron et al., 2002 respectively). 
Table 1. Reliability analysis and correlations between Overall PRS score and subscales

\begin{tabular}{|l|c|c|c|c|}
\hline All subjects & Alnarp & Umeå & Alnarp & Umeå \\
& Reliability & Reliability & Correlation & Correlation \\
& Cronbach's $\alpha$ & Cronbach's $\alpha$ & Overall PRS score & Overall PRS score \\
\hline Compatibility & 0.82 & 0.81 & 0.89 & 0.93 \\
\hline Being Away & 0.91 & 0.91 & 0.79 & 0.83 \\
\hline Fascination & 0.92 & 0.90 & 0.87 & 0.88 \\
\hline Coherence & 0.78 & 0.79 & 0.66 & 0.61 \\
\hline Scope & 0.65 & 0.77 & 0.85 & 0.79 \\
\hline
\end{tabular}

As a further check on how valid the Overall PRS score would be as a representation, correlations between the Overall score and the subscale scores were computed. Subscale mean scores were computed for every respondent based on all items in that subscale and the Overall PRS score for each respondent is the mean of the subscale means. As Table 1 shows, all subscales were significantly correlated with the Overall PRS score $(\mathrm{p}<0.05)$. All subscales have correlations values from 0.79 to 0.93 except Coherence where the correlations were 0.66 and 0.61 for the gardens in Alnarp and Umeå. Since the positive correlation between subscale and overall score might partly be due to the fact that the subscale is also included in the overall score, also the correlations between the subscales were looked at. These were all significantly correlated with each other $(\mathrm{p}<0.05)$, but with Coherence having weaker correlations to the other subscales, see Table 2.

Table 2. Correlations between subscales.

\begin{tabular}{|l|c|c|c|c|c|}
\hline $\begin{array}{l}\text { Alnarp, } \\
\text { all subjects }\end{array}$ & Compatibility & Being Away & Fascination & Coherence & Scope \\
\hline Compatibility & 1.00 & 0.69 & 0.78 & 0.42 & 0.69 \\
\hline Being Away & 0.69 & 1.00 & 0.59 & 0.35 & 0.56 \\
\hline Fascination & 0.78 & 0.59 & 1.00 & 0.39 & 0,71 \\
\hline Coherence & 0.42 & 0.35 & 0.39 & 1.00 & 0.53 \\
\hline Scope & 0.69 & 0.56 & 0.71 & 0.53 & 1.00 \\
\hline $\begin{array}{l}\text { Umeå, } \\
\text { all subjects }\end{array}$ & Compatibility & Being Away & Fascination & Coherence & Scope \\
\hline Compatibility & 1.00 & 0.74 & 0.79 & 0.47 & 0.76 \\
\hline
\end{tabular}




\begin{tabular}{|l|c|c|c|c|c|}
\hline & & & & & \\
\hline Being Away & 0.74 & 1.00 & 0.71 & 0.33 & 0.54 \\
\hline Fascination & 0.79 & 0.71 & 1.00 & 0.36 & 0.67 \\
\hline Coherence & 0.47 & 0.33 & 0.36 & 1.00 & 0.25 \\
\hline Scope & 0.76 & 0.54 & 0.67 & 0.25 & 1.00 \\
\hline
\end{tabular}

In summary, the above analyses and results show that four of the five subscales are highly connected and the fifth, Coherence, is perhaps a dimension of its own. The same picture emerged in the study by Purcell et al. 2001. In that study removing Coherence from the overall score had no effect on the result.

\subsection{Overall PRS score}

Although there can be some question marks about Coherence, the significant correlations and the result of the principal component analysis as well as the reliability analysis indicate that the use of the Overall PRS score would be sensible and valid for our purposes of investigating the perceived restorativeness of the gardens. It would also be possible to compare with studies looking at other scene types and elaborating on how the overall and subscale scores are affected by the specific content of the environments.

Based on the Overall PRS scores for each respondent for each garden a repeated measures analysis of variance was conducted with student group and image presentation order as between-subjects factors and garden as the within-subjects factor. The effect of gardens was significant $(\mathrm{F}=52.4 \mathrm{df} 1,70 ; \mathrm{p}<0.0001)$. There was a significant interaction effect between presentation orders and gardens $(\mathrm{F}=9.3$, df 1,$70 ; \mathrm{p}<0.01)$ but no interaction between student groups and gardens. Consequently the decision was made to treat the two students groups as one sample in the subsequent analyses. As can be seen in Table 3, the garden in Alnarp received a higher rating than the Umeå garden with the Overall PRS score being 7.0 for the Alnarp garden and 5.7 for the Umeå garden.

Table 3. Means and Standard Deviation (in parenthesis) for the Subscale scores and the Overall PRS score.

\begin{tabular}{|l|c|c|}
\hline & Alnarp & Umeå \\
\hline Compatibility & $6.9(1,6)$ & $5.4(1.6)$ \\
\hline Being Away & $7.5(1.6)$ & $6.6(1.8)$ \\
\hline Fascination & $6.9(1.9)$ & $5.5(1.9)$ \\
\hline Coherence & $6.3(1.7)$ & $6.8(1.9)$ \\
\hline Scope & $7.5(1.5)$ & $4.2(1.7)$ \\
\hline Overall PRS score & $\mathbf{7 . 0 ( 1 . 4 )}$ & $\mathbf{5 . 7 ( 1 . 4 )}$ \\
\hline
\end{tabular}




\subsection{Subscale scores}

To analyse whether different garden designs affect the results on subscale level, profiles with the subscale scores for the two gardens were made, see Figure 4.

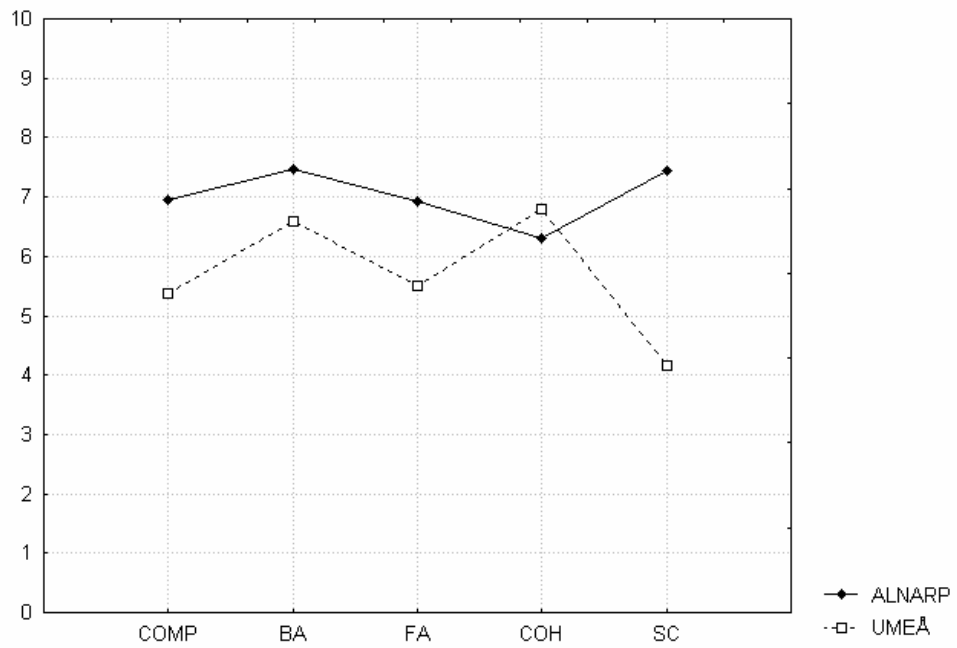

Figure 4. Line plot of subscale scores showing profiles for the two gardens. Alnarp is represented by a line and Umeå by a dotted line.

Looking at the profiles for the gardens, Compatibility, Being Away and Fascination seem to behave alike for the two gardens whereas Coherence and Scope differ. Looking at the values of the subscales scores, the garden in Alnarp receives higher scores than the garden in Umeå for all subscales except Coherence. Coherence is also the subscale with least difference due to garden. Scope is the subscale that scores most differently. In an attempt to find an explanation for the great difference between the scores for Scope, a check on the specific items was made. Four items $(2,18,22$ and 27) follow the same direction as the subscale total score, see Table 4, that is a much lower score for the smaller enclosed garden in Umeå than for the garden in Alnarp, with more open views. However, there was no such difference in item 13. Correlations also show the same pattern, as items 2, 18, 22 and 27 all are significantly correlated $(\mathrm{p}<0.05)$ with most other items in Scope but item 13 is never significantly correlated with any of the other Scope items.

Table 4. Means and Standard Deviation (in parenthesis) for every item in the subscale Scope.

\begin{tabular}{|l|l|l|}
\hline Means for every item in Scope & \multicolumn{2}{|l|}{} \\
\hline Item s in Scope & Alnarp & Umeå \\
\hline Item 2) I find this place very spacious & $8.3(2.0)$ & $3.6(2.2)$ \\
\hline $\begin{array}{l}\text { Item 13) This place has the quality of being a whole world to } \\
\text { itself }\end{array}$ & $7.5(2.5)$ & $7.9(2.0)$ \\
\hline
\end{tabular}




\begin{tabular}{|l|l|l|}
\hline Item 18) It seems like this place goes on forever & $6.3(2.6)$ & $2.0(2.3)$ \\
\hline $\begin{array}{l}\text { Item 22) This place is large enough to allow exploration in } \\
\text { many directions }\end{array}$ & $7.5(1.9)$ & $4.4(2.5)$ \\
\hline $\begin{array}{l}\text { Item 27) There are few hard boundaries here to limit my } \\
\text { possibilities of wandering about }\end{array}$ & $7.7(2.4)$ & $2.9(2.6)$ \\
\hline
\end{tabular}

\subsection{Preference}

The mean preference for the gardens is generally higher than the Overall PRS score. To assess the relationship between preference and the Overall PRS score, Pearson correlation coefficients were calculated. The correlations were both high and significant $(\mathrm{p}<0.0001)$, see Table 5.

Table 5. Mean preference, Overall PRS score and Correlations. Standard Deviation in parenthesis.

\begin{tabular}{|l|c|c|}
\hline & Alnarp & Um eå \\
\hline Preference & $7.7(2.1)$ & $6.7(2.4)$ \\
\hline Overall PRS score & $7.0(1.4)$ & $5.7(1.4)$ \\
\hline Correlation Preference and Overall PRS Score & 0.78 & 0.80 \\
\hline
\end{tabular}

\section{Discussion}

\subsection{Overall PRS scores in relation to categorisation of scene types}

The Overall PRS scores for the gardens range from 5.7 to 7.0 on an eleven-point scale, which means that both the Alnarp and Umeå garden are likely to promote restoration. As stated in the introduction it has been important in this study to make close comparisons with previous studies concerned with the perception of the physical, restorative environment as these studies are very few. Figure 5 thus shows the Overall PRS scores for all scene types previously studied by Purcell et al., 2001 and Peron et al., 2002 as well as the Overall PRS score for both gardens in this study. It is notable that no scene types studied so far have received extremely high or low Overall scores even though very extreme scene types like Desert and Polar Region have been included. In the Alnarp set half of the images have buildings in them and even if there are images showing quite wild, free growing less tended areas, the site cannot be described as having a wilderness character. There have been different suggestions and results concerning what type of nature is most preferred and most restorative. Arguments have been made for wilderness (Hartig et al., 1991; Purcell et al., 2001) while other studies have suggested everyday nature (Korpela and Hartig, 1996). For instance, some of the very remote wild scene types like Polar Region or Desert do not seem to be perceived as highly restorative (Peron et al., 2002). 
When looking at Figure 5 the scene types in the lower half of the diagram are dominated by built elements while the scene types in the upper half are predominantly natural, with nature areas as well as more mixed built/natural environments. However, it is difficult to make anything more than a broad generalisation of this pattern, as most previous studies do not describe the studied scene types in such a manner that it is possible to evaluate their actual degree of built and/or natural character. More detailed and controlled criteria would provide us with a possibility to understand why, for instance, the scene types Lakes and Industrial Zone have received different ratings in different studies and why Skyscraper is considered more restorative than Houses, as shown in Figure 5. In one sense Figure 5 supports the general idea of nature being more restorative than built environments. Still, it also shows that the type of nature, and the amount of natural elements, present in the scene type can vary a lot.

The gardens' positions fit into this pattern. Both are mixed built environments but the Alnarp garden, with a more natural character and open views of fields within the garden, places itself above the Umeå garden that is enclosed by buildings. The Alnarp garden has a score comparable with very natural environments like Lakes and Rivers, as well as more mixed environments like Country house with cultivated fields and Village in mountains. The Umeå garden has surrounding buildings clearly visible in all pictures but there is also very much greenery in front of the houses. This makes the position of the garden fit in above built environments like Square, Airport and Theatre but below the most natural environments. The different scores for the gardens as well as their relative position in Figure 5 point to the possible usefulness and capacity of the PRS to discriminate between scene types with regard to the restorative potential.

However, future studies need to collect data on both a greater number of different scene types and a greater number of examples within every type. These also need to be more controlled in sampling and well-defined in description concerning environmental content. For instance attempts have been made to define naturalness by using measurable geometric properties (Hagerhall et al., 2004; Hagerhall, 2005). 


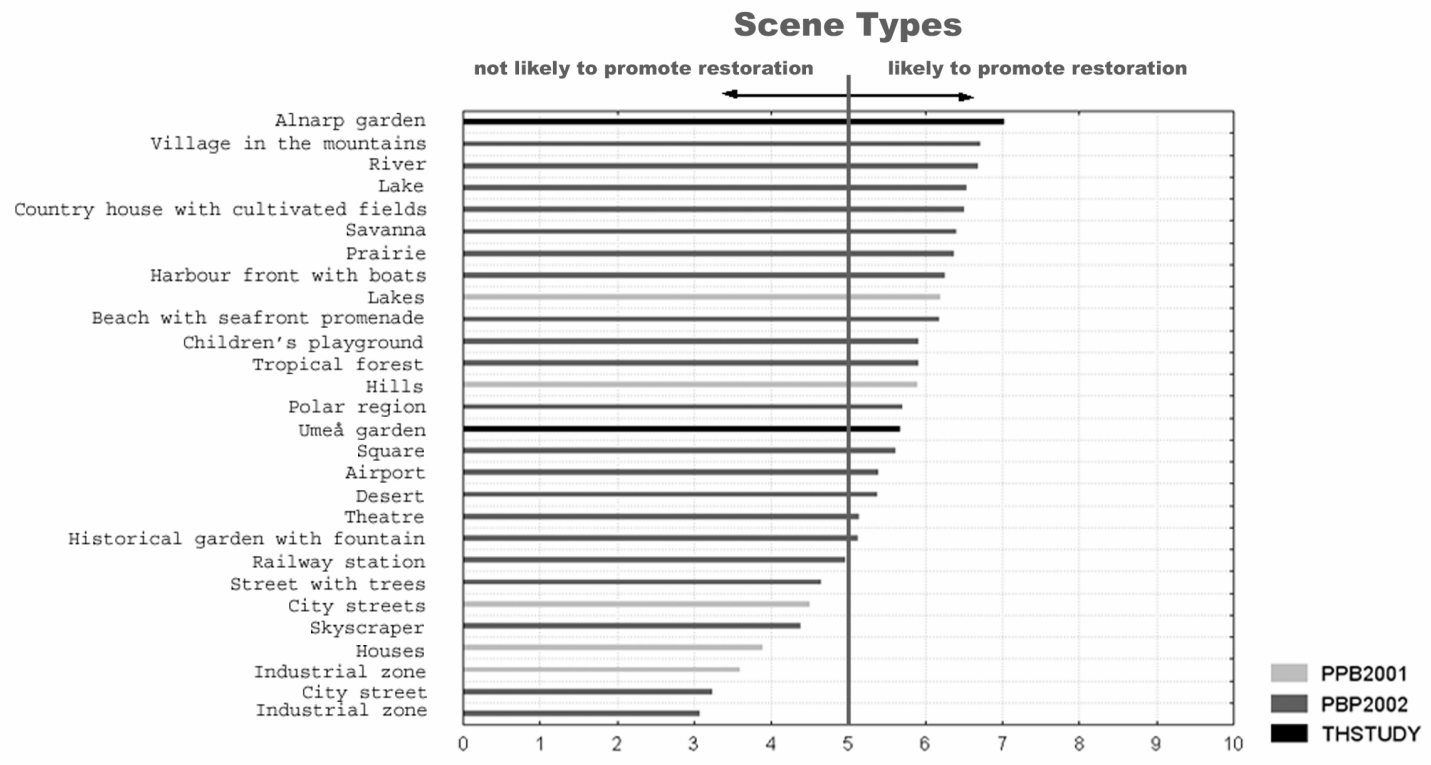

Figure 5. Illustration of Overall PRS scores from different studies. (PPB2001= Purcell et al., 2001; PBP2002= Peron et al., 2002; THSTUDY= this study).

Many scene types defy such simple categorisations as the concepts of built, human induced change or naturalness. Gardening is human induced change in a very particular and purposeful way, building a world of your own, which is dependent on both the built and the natural component. It is a transition zone between private and public and its physical expression is most often controlled by the owner/user. The growing research on restorative environments show that the explanation for the restorative value can not only be looked for in the environmental content but it is a complex construct of environmental content and factors connected to people's needs and inclinations (Scopelliti and Giuliani, 2005). Results in previous studies have shown that the restorative capacity of a place seems to be connected to places considered attractive and that favourite places have a high restorativeness (Galindo and Hidalgo, 2005; Korpela and Hartig, 1996; Korpela et al., 2001). A private garden is likely to have natural elements and also to be designed to meet the specific needs and inclinations of that user and would thus have particular restorative potential for that individual.

\subsection{Interpretation of the differences in subscale scores}

Earlier studies have indicated that the PRS is sensitive at the subscale level (Korpela and Hartig, 1996; Korpela et al., 2001). The results in this study are consistent with that view as the subscale scores varies with regard to environmental content.

The originally used concept of Extent (which in the PRS is measured by Scope and Coherence, (Hartig et al., 1996; Purcell et al., 2001) refers to scope on both a more physical level, i.e. size, and a more conceptual level, such as scope in time. Kaplan states, 'a restorative environment must be of sufficient scope to engage the mind' (Kaplan, 1995, p. 173). In our view the individual Scope items included in the PRS, are likely to trigger a rating based more on the directly visible size aspect of scope in the environment, at least with the type of 
environments used in our study. It is therefore not surprising to see that one of our prime selection criteria, difference in physical size, indeed leads to a very different score for the subscale Scope for the two gardens. As the size of the gardens seems to affect Scope very much this consequently also has a great impact on the Overall PRS score. The question is whether Scope is a sensible subscale of perceived restorativeness or if it is just a measure of physical size? It could be argued that the construction of the Scope items in the current PRS form emphasize physical size in a way not fully in line with the original concept of Extent and its connection to perceived restorativeness. When looking at the questions per se and the means for the items in Scope, see Table 4, it seems like all items except item 13 are measures of physical size. With 4 out of 5 questions emphasizing the physical size aspect, a small garden like Umeå suffers a lot although it is clearly perceived as a 'whole world to itself' as measured by item 13. This aspect of 'having the quality of being a whole world to itself', can thus in our view indeed be enhanced by design. The current construction of the PRS leads to a situation of 'the bigger the better' when it comes to Scope's contribution to perceived restorativeness. Based on experience it is common knowledge that this is not always true. It is probably more the case that the actual restorative capacity in relation to size does not increase more after we have reached a 'sufficient scope'. In a planning context the key is to have sufficient space to enable design that can enhance the quality of the place as a world to itself, in other words an interaction of optimal size in relation to the design.

The built - natural character of the gardens was our second sample selection criteria. Both gardens have a deliberately structured design, but the difference in size has an impact on the expression of this built - natural character. Structural properties, such as the differences in physical arrangement and order, would be picked up by the subscale Coherence (Herzog et al., 2003). The smaller Umeå garden has to make more efficient use of the available space and can also keep a very high maintenance level throughout the whole garden. The bigger Alnarp garden has more space available. This also means that there are transition zones between the different parts of the garden and that the perceived care and maintenance then also varies more between different parts of the garden. For these reasons the Umeå garden may be perceived as more controlled by human influence and thus have a less natural expression. As can be seen in Figure 4 there is surprisingly little difference in the Coherence scores between the gardens. However, this difference is worth noticing, as this is the only subscale where the garden in Umeå received a higher score than Alnarp. It has been suggested by Sugiyama (2004) that naturalness is a multidimensional construct, with the natural elements having a positive effect on restorativeness and preference while contrarily the rather untidy appearance of nature contributes negatively to preference. In the Sugiyama study the factor untidiness was made up of the adjectives unclutteredness, maintenance and efficiency. Thus, in relation to our study it can be said that we have two types of garden naturalness, a tidy (well maintained and efficient) natural in Umeå and another with more untidy naturalness in Alnarp. The different types of garden naturalness impact the different subscales in different ways. More green elements might enhance Fascination while if untidy lower Coherence.

In design of urban environments we are often faced with restrictions due to various physical conditions of the place, planning regulations or economic issues concerning management and care etc. However, with knowledge of how differences in design are correlated with the different subscales we can in a planning situation make the most of a place. Given the circumstances different aspects of restorativeness can be used to achieve as high overall perceived restorativeness as possible on a location or to actively enhance chosen dimensions 
of the restorativeness (Fascination, Being Away, Coherence etc) in relation to the purpose and intended use of a particular environment. Seen in relation to other studies pointing to the relative effectiveness of the predictors (Herzog et al., 2003) this opens possibilities for a conscious and efficient use of ART theory in physical planning practice.

In the Attention Restoration Theory (Kaplan, 1995) it is said that nature is particularly well endowed with fascinating characteristics and attending to those patterns is effortless. According to Kaplan (1995) fascination is central and necessary to a restorative experience, while the other three components are labelled important but additional (p. 172). However, in this study Being Away is more important than Fascination. High Being Away seems to be characteristic for gardens (see Figure 4). For the garden in Umeå Being Away and Coherence contribute most to the Overall PRS score. For Alnarp it is Being Away together with Scope. The importance of Being Away is interesting to notice. According to the results gardens induce a strong feeling of Being Away. At the same time gardens are often nearby residential areas and workplaces and visiting gardens does not require travelling long distances. This mental aspect of Being Away is thus important for restoration and perhaps similar to the Scope item 13 for which both gardens also had a high and unifying score. "This place has the quality of being a whole world to itself" is, as we suggested before, a quality that can be enhanced by purposeful design.

Our hypothesis that landscape architecture students might be particularly sensitive to detecting visual differences in outdoor environments was not verified in this study. Whether this is a result relating to the subjects or the scene type we are not able to tell.

\subsection{The relation between preference and perceived restorativeness}

Earlier studies (Purcell et al., 2001) have shown large correlations between the PRS and preference, however not as big as in this study. The high correlation between preference and the Overall PRS score, see Table 5, adds support to the hypothesis stated by Purcell et al. (2001) and Staats et al., (2003) that preference involves implicit expectations for restoration.

In the studies Purcell et al. (2001) and Peron et al. (2002) the means for the preference score were generally lower than the Overall PRS score for the scene types. In Purcell et al. (2001) the means for preference varied from 1.2-5.8 in relation to variations in means from 3.6-6.2 for the perceived restorativeness. For the scene type gardens the relationship is the opposite. Here the mean preference is higher (6.7 and 7.7) than the Overall PRS score (5.7 and 7.0). Gardens thus seem to have some particular properties that are adding to preference, apart from the perceived restorative value.

\section{Conclusion}

The PRS showed that gardens are likely to be restorative, which confirms previous results for other mixed scenes (Peron et al., 2002). The scale also proved itself capable of discriminating between two examples of the same scene type. One scene type can, as this study shows, include environments that are significantly different in perceived restorativeness. The difference in score between the gardens follows a general pattern where scene types seem to arrange themselves from low to high-perceived restorativeness based on the built - natural 
character of the environment. Furthermore, the results of this study point to that the PRS is sensitive, particularly at subscale level, to design differences on a more detailed level. The results highlight the need for more elaborate sampling of environments in future studies to fully understand the relationship between the physical expression of a place and its potential of being restorative. This would enable more purposeful design of restorative environments.

\section{Acknowledgement}

This work has been financially supported by Rector's Strategic Funds at the Swedish University of Agricultural Sciences, SLU.

\section{References}

Galindo, M.P., Hidalgo, M.C., 2005. Aesthetic preferences and the attribution of meaning: Environmental categorization processes in the evaluation of urban scenes. International Journal of Psychology 40, 19-26.

Gifford, R., Hine, D.W., Reynolds, D.J.JR., Shaw, K.T., 2000. Decoding modern architecture. A lens model approach for understanding the aesthetic differences of architects and laypersons. Environment \& Behavior 32, 163-187.

Hagerhall, C.M., 2005. Fractal dimension as a tool for defining and measuring naturalness. In: Martens, B., Keul, A.G. (Eds.), Designing Social Innovation - Planning, Building, Evaluating, Hogrefe \& Huber, Cambridge, MA, pp. 75-82.

Hagerhall, C.M., Purcell, T., Taylor, R., 2004. Fractal dimension of landscape silhouette outlines as a predictor of landscape preference. Journal of Environmental Psychology 24, 247-255.

Hartig, T., Mang, M. Evans, G.W., 1991. Restorative effects of natural environment experiences. Environment \& Behavior 23, 3-26.

Hartig, T., Kaiser F.G., Bowler, P.A., 1997a. Further development of a measure of perceived environmental restorativeness. Working paper No. 5, Institute for Housing Research, Uppsala University, Gävle.

Hartig, T., Barnes, M., Cooper Marcus, C., 1999. Conclusions and prospects. In: Cooper Marcus, C., Barnes, M. (Eds.), Healing gardens. Therapeutic benefits and design recommendations, Wiley \& Sons, New York, pp.571-596.

Hartig, T., Korpela K., Evans, G.W., Gärling, T., 1996. Validation of a measure of perceived environmental restorativeness. Göteborg Psychological Reports, 26:7, Department of Psychology, Göteborg University, Göteborg.

Hartig, T., Korpela, K., Evans, G.W., Gärling, T., 1997b. A measure of restorative quality in environments. Scandinavian Housing \& Planning Research 14, 175-194.

Health Council of the Netherlands and Dutch Council for Research on Spatial Planning, Nature and the Environment, 2004. Nature and health. The influence of nature on social, psychological and physical well-being. Health Council of the Netherlands and RMNO, publication no. 2004/09E; RMNO publication nr A02ae, The Hague. 
Hernandez, B., Hidalgo, M.C., Berto, R., Peron, E., 2001. The role of familiarity on the restorative value of a place: Research on a Spanish sample. IAPS Bulletin 18, 22-24.

Herzog, T.R., 1985. A cognitive analysis of preference for waterscapes. Journal of Environmental Psychology 5, 225-241.

Herzog, T.R., 1987. A cognitive analysis of preference for natural environments: Mountains, canyons, and deserts. Landscape Journal 6, 140-152.

Herzog, T.R., Maguire, C.P., Nebel, M.B., 2003. Assessing the restorative components of environments, Journal of Environmental Psychology 23, 159-170.

James, W., 1892. Psychology: the briefer course. Holt, New York.

Kaplan, R., Kaplan, S., 1989. The Experience of Nature: A Psychological Perspective. Cambridge University Press, New York.

Kaplan, S., 1987. Aesthetics, affect, and cognition: Environmental preference from an evolutionary perspective. Environment and Behavior 19, 3-32.

Kaplan, S., 1995. The restorative benefits of nature: Toward an integrative framework. Journal of Environmental Psychology 15, 169-182.

Kaplan, S., Kaplan, R., 1982. Cognition and Environment: Functioning in an Uncertain World. Praeger, New York.

Kaplan, S., Kaplan, R., Wendt, J.S., 1972. Rated preference and complexity for natural and urban visual material. Perception and Psychophysics 12, 354-356.

Korpela, K., Hartig, T., 1996. Restorative qualities of favorite places. Journal of Environmental Psychology 16, 221-233.

Korpela, K.M., Hartig, T., Kaiser, F.G., Fuhrer, U., 2001. Restorative experience and self-regulation in favourite places. Environment \& Behavior 33, 572-589.

Laumann, K., Gärling, T., Stormark, K.M., 2001. Rating scale measures of restorative components of environments. Journal of Environmental Psychology 21, 31-44.

Peron, E., Berto, R., Purcell, T., 2002. Restorativeness, preference and the perceived naturalness of places. Medio Ambiente y Comportamiento Humano 3, 19-34.

Purcell, A.T., Lamb, R. J., 1984. Landscape perception: An examination and empirical investigation of two central issues in the area. Journal of Environmental Management 19, 31-63.

Purcell, T., Peron, E., Berto, R., 2001. Why do preferences differ between scene types?. Environment \& Behavior 33, 93-106.

Scopelliti, M., Giuliani, M.V., 2005. Choosing restorative environments across the lifespan: A matter of place experience. Journal of Environmental Psychology 24, 423-437.

Staats, H., Kieviet, A., Hartig, T., 2003. Where to recover from attentional fatigue: An expectancyvalue analysis of environmental preference. Journal of Environmental Psychology 23, 147-157. 
Sugiyama, T., 2004. Do People Really Prefer "Natural" Scenes? An Empirical Examination of Preference, Naturalness and Tidiness. In: Martens, B., Keul, A.G. (Eds.), Evaluation in progress Strategies for Environmental Research and Implementation, IAPS 18 Conference proceedings on CDRom - ISBN 3-85437-263-9. IAPS Digital Library http://iaps.scix.net/

Ulrich, R.S., 1999. Effects on garden outcomes: Theory and research. In: Cooper Marcus, C., Barnes, M. (Eds.), Healing gardens. Therapeutic benefits and design recommendations. Wiley \& Sons, New York, pp. 27-86.

Ulrich, R.S., Simons, R.F., Losito, B.D., Fiorito, E., Miles, M.A., Zelson, M., 1991. Stress recovery during exposure to natural and urban environments. Journal of Environmental Psychology $11,201-230$.

Williams, A., 1999. Therapeutic Landscapes: The Dynamic Between Place and Wellness. University Press of America, Lanham. 